\title{
OPTIMAL STRUCTURE OF HYBRID RENEWABLE ENERGY SYSTEMS: A SCHEME TO REALIZE NATIONAL ENERGY GOAL
}

\author{
Obasi, Ibe B. \\ Department of Physics/Electronics \\ Federal Polytechnic, Nekede Owerri, Nigeria
}

\author{
Eze, Joseph O. \\ Department of Physics/Electronics \\ Federal Polytechnic, Nekede Owerri, Nigeria
}

\begin{abstract}
Substantial rise in the costs of conventional energy sources and open alertness of the necessity to moderate global warming have reinvigorated several countries to make available fresh energy strategies that encourage the renewable energy applications. Such renewable energy sources like solar, wind, hydro-based energies, etc. are pleasant to the environment and have latency to be in extensive use. Forming a hybrid system by combining these renewable energy sources in addition, to back-up units can provide reliable power supply that will meet all load demand conditions compared to stand alone of such systems with additional economic benefits and environment friendliness. The foremost parameter in the hybrid system is the optimal sizing of the system constituents that are adequate to meet entirely the load requirements with possible minimum outlay and operating costs. There are numerous investigations about the sizing and optimization of hybrid renewable energy systems since the current widespread application of renewable energy sources. In this perception, this study offers a comprehensive investigation of such optimal sizing techniques that can make substantial contributions to extensive renewable energy perception by improving the system applicability in economic perspectives.
\end{abstract}

Keywords: Hybrid, optimal, sizing, renewable energy, software, optimization

\section{INTRODUCTION}

The world is facing a large problem of meeting its energy need. Sharma (2015) and many others attributed that at the present time, a great share of the energy supplies all around the world is provided from conventional energy sources like coal, natural gas, crude oil, etc. Furthermore, Rehman et al., (2007) reported that the exponential growths in energy demands are causing a quick growth in requirement of conventional fossil fuels. Reports by Shaahid and Elhadidy (2007) documented that, these conventional sources are limited and fast diminishing, which in turn impends the equilibrium of forthcoming energy demand/generation. Furthermore, the instability of resource and price for the conventional sources and adverse influences on governmental equilibrium between exporting and importing countries offer important considerations on the future of conventional energy.

An environmental consequence of fossil fuel use like greenhouse gas emission that may cause global warming is a burning issue in global discussion. Thus, Kyoto agreement on global reduction of greenhouse gas emissions provided for averting this problem by decreasing the reliance on conventional energy systems. This condition is binding for the developed and developing countries. Realization in overcoming the above-mentioned difficulties presently facing the world necessitates long-term possible activities for sustainable development. Hepbasli (2008) defined sustainable energy system as a cost-effective, reliable, and environment friendly energy system that effectively utilizes local resources and networks. Renewable energy sources according to Kornelakis, (2010) are capable of providing a sustainable energy supply and are predicted to be among the most efficient and effective results. Renewable energy system types, has features that are adaptable to certain uses. The renewable energy sources do not emit gaseous or liquid toxins during operation, thus providing a major advantage over the conventional systems. A shortcoming of the renewable energy systems are their irregular nature and reliance on weather conditions. Another concern with the renewable energy production agreeing with Chen et al. (2007) is that it may not totally fulfill the power demand of the load.

Shaahid and Elhadidy (2007), Ekren and Ekren (2010) agreed that these shortcomings can be resolved by incorporating renewable energy systems resources in a appropriate hybrid mixture which delivers the prospective to increase the system efficiency and reliability. These hybrid systems can be configured either as a stand-alone or in grid-parallel application modes, and dependent on factors such as grid availability, cost of grid supplied electricity, and meteorological conditions in the application site in agreement with Erdinc and Uzunoglu (2012).

Literature have reported various optimized hybrid system techniques for sizing, frrom genetic algorithm, simulated annealing, to particle swarm optimization. In addition, several sizing tools such as Hybrid Optimization Model for Electric Renewables (HOMER) have been developed and widely utilized in many applications. This effort reports through review by presenting the novel hybrid system sizing methods and aims at researchers to comprehend present trends about optimum sizing.

\section{METHOD AND MATERIALS}

\section{A. System sizing methods}

The optimum design of hybrid renewable energy systems is a well-researched topic. Ter-Gazarian and Kagan (1991) acknowledged the system design problem as being dependent 
on type and sizing of generation units, configuration of the power system and its location, and the system needs to meet load requirements at minimum cost. The design of the hybrid renewable energy systems are valued by its lifespan cost and emission. The lifetime cost typically consists of the variable cost and the fixed cost. The former being the operational cost and the later are capital cost and the maintenance cost

In computing the lifespan cost, changes in the economic value over time is considered. Consequently, optimal hybrid system configuration pursues an arrangement of generator types and sizes that result in the lowest lifetime cost and/or emission. Anglani and Muliere (2010) in their study supposed that among all possible hybrid system configurations, the configuration with the least Net Present Value is acknowledged as the optimal configuration or the optimal design. Many software tools provide the optimal design conditions that can be useful for real time system integration and are commercially available. Furthermore, several optimization techniques are also been applied by various researchers for the sizing of hybrid renewable energy systems. HOMER developed by National Renewable Energy Laboratory (NREL), use simulation programs to compute the optimum configuration by comparing the performance and energy production cost of different system configurations.

HOMER includes several energy component models, such as photovoltaic, wind turbines, hydro, batteries, fuel generators, electrolysis units, and fuel cells, and evaluates suitable options considering cost and availability of energy resources. HOMER design also considered grid connection in procedure. The software requires initial information including energy resources, economical and technical constraints, energy storage requirements and system control strategies. Inputs like component type, capital, replacement, operation and maintenance costs, efficiency, operational life, etc. are also required (Erdinc and Uzunoglu, 2012).

A number of other software tools are also available for designing of hybrid systems, Schmitt (2002) referred to the Simulation of Photovoltaic Energy Systems (SimPhoSys); Isherwood et al. (2000) discussed to the Hybrid Power System Simulation Model (HYBRID2); Lopez et al. (2009) argued the Grid-connected Renewable Hybrid Systems Optimization (GRHYSO); Belfkira et al., (2009) reasoned on the Dividing Rectangles (DIRECT); Berberi (2009) worked on the Determining Optimum Integration of RES (DOIRES) and Mousa, et al. (2010) discussed The General Algebraic Modeling System (GAMS).

\section{B. System sizing optimization methods}

A number of methods are available for optimizing the sizing of hybrid systems some of which are evaluated in the following subsections.

\section{Genetic algorithm optimization method}

Genetic algorithm is an optimization method based on the genetic process of biological organisms. By mimicking this process, it has capability to provide answers to complex real world problems. Genetic algorithm concept is widely utilized in many types of applications. Holland (1975) reported that Genetic algorithm based sizing methodology uses the given input data to provide an iterative procedure utilizing the genetic algorithm operators until it arrives at a predefined termination conditions or maximum iteration number. Studies by Chen and Huang (2008) classified the genetic algorithm to consist of five modules. These are an initial random population generator, a fitness evaluation unit and genetic operators for selection, crossover and mutation operations. With the random population generation at the start, Genetic algorithm offers random sizes for the hybrid system components that satisfy the load demand/power generation balance at each step. Yan and Fang (2008) deposited that the random results are evaluated according to the defined fitness function. The selection operator selects the predefined percentage of the initial population due to their fitness value.

Using these selected results; crossover operator provides new possible results with the aim of achieving higher fitness values. For illustration, for a photovoltaic-wind hybrid system, the selection operator may choose two different results of $2 \mathrm{~kW}$ photovoltaic system, $1 \mathrm{~kW}$ wind turbine, and $2.5 \mathrm{~kW}$ photovoltaic system, $0.5 \mathrm{~kW}$ wind turbine. Using a sample crossover operation, two new possible results that can either have a lower or greater fitness value than present results can be provided as $2.5 \mathrm{~kW}$ photovoltaic system, $0.5 \mathrm{~kW}$ wind turbine and $2 \mathrm{~kW}$ photovoltaic system, $1 \mathrm{~kW}$ wind turbine. The new population is created from the results obtained by the selection operator and the new results created by the crossover operator. Then, the selection of the results with greater fitness values and creation of a new population continue at each iteration during the iterative procedure. During the iterative process, a mutation operator can be applied to prevent being stuck at a local minimum. The utmost important advantage of genetic algorithm for use in hybrid system sizing is that it can easily jump out of a local minimum and has quite efficient capability to find the global optimum.

\section{Particle swarm optimization method}

Particle swarm optimization is an optimization technique based on the movement and intelligence of swarms and belongs to evolutionary computation techniques. The structure of the particle swarm optimization is similar to the genetic algorithm based method, the input data of the particle swarm optimization based methodology are the meteorological conditions. The process of particle swarm optimization based sizing methodology is a population-based stochastic optimization procedure. Lee and Chen (2009); Phuangpornpitak et al. (2010) both referred potential results in particle swarm optimization 
population as a particle. In this method, the co-ordinates of each particle represent a possible solution associated with position and velocity vector. Chung et al. (2008) and Ardakani et al. (2010) emphasized that each particle is initialized by a random velocity and is flown through the search space. At each iteration, particle move towards an optimum result, through its present velocity, personal best result obtained by them so far are the global best result obtained by all particles. As an example to better examine the process of particle swarm optimization methods, a hybrid photovoltaic-wind system can be evaluated. For instance, the present position of a particle in search space at iteration " $\mathrm{x}_{\mathrm{i}}$ " is presumed as $2 \mathrm{~kW}$ photovoltaic system, $1.5 \mathrm{~kW}$ wind turbine on $\mathrm{x}-\mathrm{y}$ diagram. Besides, the present position of the particle having the best fitness value among all population at the present iteration is presumed as 2 $\mathrm{kW}$ photovoltaic system, $2.5 \mathrm{~kW}$ wind turbine. It is also presumed in particle swarm optimization that all the particles in the population have great knowledge on the present positions of its neighbors and the particle having the best position. Thus, the particle at coordinate $(2,1.5)$ inspects the search space and increases its present velocity on the $\mathrm{x}$ axis to meet the particle with the best coordinate at $(2,2.5)$.

All the particles in the population apply the same procedure at each iteration and thus a group movement is reached with this process. The iteration procedure continues until a predefined end condition is reached in agreement with studies conducted by Sanchez et al. (2010 and Dehghan et al. (2009). However, both genetic algorithm and particle swarm optimization algorithms have excellent efficiency by using similar iterative searching methods, the later have some advantages over the former. An important feature of this method is that it is based on a simple concept involving few equations that are easy to implement in a software environment. Consequently, the computation time is short and it requires few memories as reported by Avril et al. (2010). However, the reliability for finding the global optimum of a search space is lower than genetic algorithm based method and this method is less suitable than the former for problems consisting of more than three parameters as it is based on coordinate definition of particles and defined on $\mathrm{x}, \mathrm{y}, \mathrm{z}$ plane.

Genetic algorithm and the particle swarm optimization methods have a wide use in hybrid system sizing studies. Lagorse et al. (2009); Kalantar and Mousavi (2010) applied genetic algorithm to design a photovoltaic-wind hybrid unit and photovoltaic, wind, wind-photovoltaic hybridization respectively. Wang and Singh (2006) and Zhao et al. (2009) used particle swarm optimization to suggest photovoltaic-wind hybrid systems.

\section{Simulated annealing optimization method}

Kirkpatrick et al. (1983) introduced the simulated annealing as a general optimization technique for solving combinatorial optimization problems. In the simple algorithm of simulated annealing for hybrid system sizing application, at each iteration a candidate move is randomly selected and this move is accepted if it leads to a result with an improved objective function value than the present result. Otherwise the move is accepted with a probability that will be determined by the deterioration of the objective function value based on Metropolis conditions. For example, the hybrid photovoltaicwind system considered in particle swarm optimization can be examined again. The present best result in the population at iteration $\mathrm{x}_{\mathrm{i}}$ is presumed to be $2 \mathrm{~kW}$ photovoltaic system, $2.5 \mathrm{~kW}$ wind turbine. Additional new answer in the population is also presumed as $2 \mathrm{~kW}$ photovoltaic system, $1.5 \mathrm{~kW}$ wind turbine. If this new answer has a better fitness value than the present best result in the population, then the new result is accepted. Alternatively, if this new result has a worse fitness value than the present best result in the population, then the new result may also be acknowledged and considered for the new population at the next iteration subject to the variance between its fitness value and the best fitness value. The use of simulated annealing in hybrid system sizing is not so widespread as genetic algorithm or particle swarm optimization, but is a presently emergent area of research. Instances of researches based on simulated annealing include the work of Ekren and Ekren (2010) for wind-photovoltaic-battery hybridization and Giannakoudis et al. (2010) for a renewable-hydrogen storage combination based hybrid system.

\section{RESULTS AND DISCUSSION}

\section{A. Ant colony optimization method}

Previous studies proposed the ant colony optimization as a technique for optimization. The procedure development was by inspiration by the observation of ant colonies (Meziane et al., 2005). In reference to our earlier photovoltaic-wind system instance, in the search space, each ant is originally placed in a separate random place. The present coordinates of an ant in the search space can be given in $\mathrm{x}-\mathrm{y}$ plane. The present position of the mentioned ant is assumed to be $2 \mathrm{~kW}$ photovoltaic system, $1.5 \mathrm{~kW}$ wind turbine. This ant transports from its position and to a second better position at the next iteration. This next movement may be realized to $2 \mathrm{~kW}$ photovoltaic system, 1.4 $\mathrm{kW}$ wind turbine, $2 \mathrm{~kW}$ photovoltaic system, $1.6 \mathrm{~kW}$ wind turbine, $2.1 \mathrm{~kW}$ photovoltaic system, $1.5 \mathrm{~kW}$ wind turbine, and $2 \mathrm{~kW}$ photovoltaic system, $1.5 \mathrm{~kW}$ wind turbine, considering the better level in these possible options. Like this ant, all of the ants in the colony search around their positions and select their next movement to a better level. Consequently, all the search space is considered and the colony starts to move as a group in the next levels of the iterative procedure. As long as pre-defined conditions are reached like the desired rate of ants finding the food space or maximum number of iterations, the procedure is terminated and the results are presented (Blum, 2006).

Ant colony optimization is promising for future applications and may obtain a significant place especially in areas with similar group movement based procedures. The advantages and 


\section{International Journal of Engineering Applied Sciences and Technology, 2020 Vol. 5, Issue 1, ISSN No. 2455-2143, Pages 145-150 \\ Published Online May 2020 in IJEAST (http://www.ijeast.com)}

disadvantages for particle swarm optimization method are also valid for ant colony optimization.

\section{B. Artificial immune system optimization method}

Artificial immune optimization system procedure is inspired by immunology, immune function and principles observed in nature is suggested as a new branch in computational intelligence. For the artificial immune system to execute its function, it has to distinguish between its own cells of body and foreign pathogens. Thereafter, it performs an immune response in foreign cell. The structure of the antigen population varies at each iteration with the evaluation of the population performance during elimination of the infeasible solutions. Old pathogens with lower fitness values are replaced with new ones in order to maximize the group fitness value. Artificial immune system optimization system includes selection and mutation operators that can significantly enhance the probability of the algorithm to find the global optimum point Aydin et al. (2011), it is analogous to genetic algorithm optimization system, The photovoltaic-wind instance given for genetic algorithm is equally valid for artificial immune system optimization method. However it has lesser implementation due to its limited ability to deal with large number of parameters.

\section{Other methods}

Numerous other methods that can be developed in the future studies with the aim of efficiently and economically size hybrid energy systems have been reported. Hennet and Arda, (2008) reported the game theory, Kalinli and Karaboga (2004) the tabular search, Panigrahi et al. (2011) the bacterial foraging procedure, and Marinaki et al. (2011) the honey bee mating procedure, these can be suggested as the commonly utilized methods in other kinds of applications.

\section{CONCLUSIONS}

Upsurge of the world energy demand and environmental implications involving conventional energy consumption have encouraged the extensive investigation on renewable energy technologies to substitute the traditional fossil fuels. Mainly, hybrid systems, which may be defined as a combination of renewable and back-up units or conventional energy sources, turn out to be an appropriate answer to the challenges that the world faces nowadays for sustainability concern of energy supply and environmental protection. The geographical landscape of the area, potential energy resources are obtainable and the form of energy requirements, the hybrid energy systems can be advanced and optimized so as to meet the needs of the area. The optimal sizing of these renewable energy based hybrid systems can considerably increase the economic and efficiency of power supply as well as stimulating the widespread use of such environment friendly sources. Diverse sizing methods can be applied to reach a technical and economically viable optimum hybrid renewable energy system.
Therefore, economical obstacles for improved perception of renewable energy can be relatively overcome. A number of sizing methodologies comprising existing software's as well as possible varying optimization techniques are inspected in the content of this study. Every sizing methodology has its own features and many more new methodologies have the possibilities for future application in this aspect. The choice of the appropriate method may change due to the type of application, user requirements, etc. In short, each developed sizing method has the possibility to considerably encourage the usability of renewable energy systems and consequently, has a great significance in renewable energy space.

\section{REFERENCES}

[1] Anglani, N., \& Muliere, G. (2010). Analyzing the impact of renewable energy technologies by means of optimal energy planning. In: 9th international conference on environment and electrical engineering (EEEIC), (pp. 15) EEEIC.

[2] Ardakani, F. J., Riahy, G., \& Abedi, M. (2010). Design of an optimum hybrid renewable energy system considering reliability indices. In: 18th Iranian conference on electrical engineering (ICEE), (pp. 842-847), ICEE.

[3] Avril, S., Arnaud, G., Florentin, A., \& Vinard, M. (2010). Multi-objective optimization of batteries and hydrogen storage technologies for remote photovoltaic systems. Energy, 35(12), 5300-5308.

[4] Aydin, I., Karakose, M., \& Akin, E. (2011). A multiobjective artificial immune algorithm for parameter optimization in support vector machine. Applied Soft Computing, 11(1), 120-129.

[5] Belfkira, R., Barakat, G., Nicolas, T., \& Nichita, C. (2009). Design study and optimization of a grid independent wind/PV/diesel system. In: 13th European conference on power electronics and applications (EPE'09), (pp. 1-10) EPE.

[6] Berberi, P., Thodhorjani, S., \& Aleti, R. (2009). Integration optimization of alternative sources of energy in a remote region. In: ELECTROMOTION, (pp. 1-4) ELECTROMOTION.

[7] Blum, C. (2005). Ant colony optimization: Introduction and recent trends. Physics of Life Reviews, 2(4), 353-373.

[8] Chen, F., Duic, N., Alves, L. M., \& da Graça Carvalho, M. (2007). Renew islands-Renewable energy solutions for islands. Renewable and Sustainable Energy Reviews, 11(8), 1888-1902.

[9] Chen, S. M., \& Huang, C. M. (2008). A new approach to generate weighted fuzzy rules using genetic algorithms for estimating null values. Expert Systems with Applications, 35(3), 905-917.

[10] Chung, I. Y., Liu, W., Cartes, D. A., \& Schoder, K. (2008). Control parameter optimization for a microgrid system using particle swarm optimization. In: IEEE international conference on sustainable energy technologies (ICSET), (pp. 837-842), ICSET. 


\section{International Journal of Engineering Applied Sciences and Technology, 2020 Vol. 5, Issue 1, ISSN No. 2455-2143, Pages 145-150 \\ Published Online May 2020 in IJEAST (http://www.ijeast.com)}

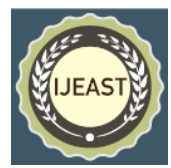

[11]Dehghan, S., Saboori, H., Parizad, A., Kiani, B. (2009). Optimal sizing of a hydrogen-based wind/PV plant considering reliability indices. In: International conference on electric power and energy conversion systems (EPECS'09), (pp. 1-9), EPECS.

[12] Ekren, O, \& Ekren, B. Y. (2010). Size optimization of a $\mathrm{PV} /$ wind hybrid energy conversion system with battery storage using simulated annealing. Applied Energy, 87(2), 592-598.

[13] Erdinc, O. \& Uzunoglu, M. (2012). Optimum design of hybrid renewable energy systems: Overview of different approaches. Renewable and Sustainable Energy Reviews, $16,1412-1425$.

[14] Giannakoudis, G., Papadopoulos, A. I., Seferlis, P., \& Voutetakis, S. (2010). Optimum design and operation under uncertainty of power systems using renewable energy sources and hydrogen storage. International Journal of Hydrogen Energy, 35(3), 872-891.

[15] Hennet, J. C., \& Arda, Y. (2008). Supply chain coordination: a game-theory approach. Engineering Applications of Artificial Intelligence, 21(3), 399-405.

[16] Hepbasli, A. A. (2008). Key review on exergetic analysis and assessment of renewable energy resources for a sustainable future. Renewable and Sustainable Energy Reviews, 12(3), 593-661.

[17] Holland, J. H. (1975). Adaptation in natural and artificial systems. Massachusetts, Cambridge, MIT Press.

[18] Isherwood, W., Smith, J. R., Aceves, S. M., Berry, G., Clark, W., \& Johnson, R. (2000). Remote power systems with advanced storage technologies for Alaskan villages. Energy, 25(10), 1005-1020.

[19] Kalantar, M., \& Mousavi, S. M. G. (2010). Dynamic behavior of a stand-alone hybrid power generation system of wind turbine, microturbine, solar array and battery storage. Applied Energy, 87(10), 3051-3064.

[20] Kalinli, A., \& Karaboga, D. (2004). Training recurrent neural networks by using parallel tabu search algorithm based on crossover operation. Engineering Applications of Artificial Intelligence, 17(5), 529-542.

[21] Kirkpatrick, S., Gelatt, C. D., \& Vecchi, M. P. (1983). Optimization by simulated annealing. Science, 220, 671680.

[22] Kornelakis, A., \& Marinakis, Y. (2010). Contribution for optimal sizing of grid-connected PV-systems using PSO. Renewable Energy, 35(6), 1333-1341.

[23] Lagorse, J., Paire, D., \& Miraoui, A. (2009). Hybrid standalone power supply using PEMFC, PV and battery modelling and optimization. In: International conference on clean electrical power (ICCEP), (pp. 135-410), ICCEP.

[24]Lee, T. Y., Chen, C. L. (2009). Wind-photovoltaic capacity coordination for a time-of-use rate industrial user. IET Renewable Power Generation, 3(2), 152-167.

[25] Lopez, R. D., Agustin, J. L. B., \& Mendoza, F. (2009). Design economical analysis of hybrid PV-wind systems connected to the grid for the intermittent production of hydrogen. Energy Policy, 37(8), 3082-95.

[26] Marinaki, M., Marinakis, Y., \& Zopounidis, C. (2010). Honey bees mating optimization algorithm for financial classification problems. Applied Soft Computing, 10(3), 806-812.

[27] Meziane, R., Massim, Y., Zeblah, A., Ghoraf, A., Rahli, R. (2005). Reliability optimization using ant colony algorithm under performance and cost constraints. Electric Power Systems Research, 76(1-3), 1-8.

[28] Mousa, K., AlZu'bi, H., Diabat, A. (2010). Design of a hybrid solar-wind power plant using optimization. In: 2 nd international conference on engineering systems management and its applications (ICESMA), (pp. 1-6) ICESMA.

[29] Panigrahi, B. K., Pandi, V. R., Sharma, R., Das, S., \& Das, S. (2011). Multi-objective bacteria foraging algorithm for electrical load dispatch problem. Energy Conversion and Management, 52(2), 1334-1342.

[30] Phuangpornpitak, N., Tia, S., Prommee, W., \& Phuangpompitak, W. (2010). A study of particle swarm technique for renewable energy power systems. In: International conference on energy and sustainable development: issues and strategies (ESD), (pp. 1-6), ESD.

[31] Rehman, S, El-Amin, I. M, Ahmad, F, Shaahid, S.M, AlShehri, A.M., \& Bakhashwain, J.M. (2007). Feasibility study of hybrid retrofits to an isolated off-grid diesel power plant. Renewable and Sustainable Energy Reviews, 11(4), 635-563.

[32] Sánchez, V., Ramirez, J. M., \& Arriaga, G. (2010). Optimal sizing of a hybrid renewable system. In: IEEE international conference on industrial technology (ICIT), (pp. 949-954), ICIT.

[33] Schmitt, W. (2002). Modeling and simulation of photovoltaic hybrid energy systems optimization of sizing and control. In: Conference record of the 29th IEEE photovoltaic specialists conference, (pp. 1656-1659), IEEE.

[34] Shaahid, S. M., \& Elhadidy, M. A. (2007). Technical and economic assessment of grid-independent hybrid photovoltaic-diesel-battery power systems for commercial loads in desert environments. Renewable and sustainable energy reviews, 11(8), 1794-1810.

[35] Shaahid, S. M., \& Elhadidy, M. A. (2007). Technical and economic assessment of grid-independent hybrid photovoltaic-diesel-battery power systems for commercial loads in desert environments. Renewable and Sustainable Energy Reviews, 11(8), 1794-1810.

[36] Sharma, P. (2015). Performance analysis of a stand-alone hybrid renewable energy power system-a simulation study. In India Conference (INDICON), Annual IEEE, (pp. 1-6), IEEE.

[37] Ter-Gazarian, A. G., \& Kagan, N. (1992). Design model for electrical distribution systems considering renewable, conventional and energy storage units. IEEE Proceedings 
C: Generation, Transmission and Distribution, 139(6), 499-504.

[38] Wang, L., Singh, C. (2006). PSO-based multidisciplinary design of a hybrid power generation system with statistical models of wind speed and solar isolation. International Conference on Power Electronics, Drives and Energy Systems (PEDES), (pp1-6), PEDES.

[39] Yan, M. T., \& Fang, C. C. (2008). Application of genetic algorithm-based fuzzy logic control in wire transport system of wire-EDM machine. Journal of Materials Processing Technology, 205(1-3), 128-137.

[40]Zhao, Y.S., Zhan, J., Zhang, Y., Wang, D. P., Zou, B. G. (2009). The optimal capacity configuration of an independent wind/PV hybrid power supply system based on improved PSO algorithm. In: 8th international conference on advances in power system control, operation and management (APSCOM), (pp. 1-7) APSCOM. 